\title{
Integration of Remote Sensing and GIS to Assess Vulnerability of Environmental Degradation in North-Western Bangladesh
}

\author{
Md. Shareful Hassan', Syed Mahmud-Ul-Islam², Muhammad Tauhidur Rahman ${ }^{3}$ \\ ${ }^{1}$ Center for Environmental Change Studies and Management, Dhaka, Bangladesh \\ ${ }^{2}$ Department of Sustainable Development, Environmental Science and Engineering, KTH-Royal Institute of \\ Technology, Stockholm, Sweden \\ ${ }^{3}$ Department of City and Regional Planning, King Fahd University of Petroleum and Minerals, Dhahran, KSA \\ Email: shareful@gmx.com
}

Received 27 August 2015; accepted 10 October 2015; published 13 October 2015

Copyright (C) 2015 by authors and Scientific Research Publishing Inc.

This work is licensed under the Creative Commons Attribution International License (CC BY).

http://creativecommons.org/licenses/by/4.0/

(c) $)$ Open Access

\begin{abstract}
Environmental degradation is a burning issue in Bangladesh. The degradation process is extremely acute in the north-western part of Bangladesh due to many environmental and anthropogenic reasons. However, initiative of research work on this issue is very crucial and urgent for regional and local planning and management. In this paper, Nachole and Niamotpur Upazilas were considered as the study area to identify and quantify environmental degradation using an integrated Geographic Information System (GIS) and Remote Sensing (RS) technique. The results of the study reveal that the area is one of the most vulnerable areas in terms of land degradation that already affected local agriculture, biodiversity, water supply and overall socio-economic livelihoods. From the modelling results, about 66,301 hectares $(90 \%)$ of land are vulnerable to land degradation, of which 24,736, 40,309 and 256 hectares of land were classified as severely, highly, and moderately vulnerable areas respectively. The overall image classification accuracy for all the resultant images was $95.40 \%$ while kappa coefficient was 0.94 .
\end{abstract}

\section{Keywords}

GIS, Remote Sensing, Landsat, DEM, Soil Degradation, Bangladesh

\section{Introduction}

Environmental degradation is one of the most concerning issues in the world. About 48.35 million square kilometres of the earth's surface are covered by desert while 5.85 million square kilometres are extremely arid, 21.5

How to cite this paper: Hassan, Md.S., Mahmud-Ul-Islam, S. and Rahman, M.T. (2015) Integration of Remote Sensing and GIS to Assess Vulnerability of Environmental Degradation in North-Western Bangladesh. Journal of Geographic Information System, 7, 494-505. http://dx.doi.org/10.4236/igis.2015.75040 
million square kilometres are arid, and 21.0 million square kilometres are semi-arid [1]. In Asian countries, about 2.6 million square kilometres areas are experiencing desertification [2]. Environmental degradation is extremely acute in the north-western part of Bangladesh in which soil erosion, depletion of soil organic matter, soil contamination by pesticide, deforestation, water pollution, dried-out surface water, loss of biodiversity, decline of ground water rate, proper land management are the main reasons. In terms of seasonal dryness and drought conditions, about 43.0 percent of the country is affected because of declining soil quality, seasonal dryness, and drought conditions [3].

Monitoring, measuring, modelling, and mapping of environmental degradation play an important role in managing natural resource for sustainable development. Over the past several decades, rapid improvements in Remote Sensing and Geographic Information Systems (GIS) allowed researchers to identify, monitor, and quantify, and map environmental degradation using various bio-physical and socio-economic parameters in various parts of the world [4]. Torrion (2002) used multi-temporal remote sensing data and multiple geospatial layers to identify and quantify land degradation in the Lake Naivasha Basin, Kenya [5]. From his study, a huge quantity of degraded soil has been identified in the north and south parts of the study area. In order to investigate environmental degradation in Nam Chun sub-watershed in Thailand, Boonruck et al. (2004) used remote sensing data and found that both deforestation and flooding were causing extensive degradation (by as much as $15 \%$ ) of cropped areas [6]. Narangerel (2001) used Normalized Difference Vegetation Index (NDVI) maps from the NOAA-AVHRR sensor with other related thematic maps to detect land degradation in the western parts of Mongolia. Derived NDVI information along with multi-temporal meteorological data suggested that significant land degradation occurred in the area and is related to several components including vegetation cover, composition of top soil, and topography [7]. Essa (2002) introduced an empirical model based on Landsat MSS, TM, and soil information to study land degradation between 1972 and 1992 along the Syrian border [4]. In his study, Revised Universal Soil Loss Equation (RUSLE) was followed using vegetation coverage, soil parameters, and land use. The results indicate that a large amount of soil has been lost during the study period. Mohamed et al. (2013) discussed land degradation issues and risk assessment of soil types in Eastern Nile delta region, Egypt [8]. They used satellite images of 1997 to 2010 and GIS techniques to find four types of degradation including water logging, soil compaction, alkalization and salinization. They developed spatial land degradation model based on their RS data, GIS, DEM and soil characteristics. The main factors found behind the degradation were anthropogenic. Baroudy et al. (2014) showed almost similar degradation types and anthropogenic causes over the Northern Nile Delta region, Egypt [9]. They analyzed soil degradation assessment using Landsat $7 \mathrm{ETM}^{+}$(for 2003) and DEM data. In addition to this analysis, the soil degradation assessment of the entire study area was identified and categorized between very high risk and low risk of chemical degradation. A recent land degradation assessment has been carried out in Damietta Governorate, Egypt by GIS and spatial analysis techniques where significant areas were found as higher risk of soil compaction and salinization [10]. Rabia (2012) developed a land degradation map of Tigray, Ethiopia using GIS spatial model [11]. In this result, it is revealed that high land degradation was caused by high soil loss due to erosion and high deficiency of soil nutrients. Thus, GIS technology has manifested massive efficiency in recent years as a special tool for land degradation assessment worldwide.

Within Bangladesh, few studies have focused on the status of land degradation, consequences, and possible solutions for different parts of the country. Gafur et al. (2003) examined the loss of soil and nutrients from watersheds in the Chittagong Hill Tracts in the south-eastern part of the country [12]. Ali (2006) studied how shrimp cultivation degraded the soil in the south-western coastal areas of Bangladesh and reduced the yield in rice production in the small rural villages [13]. Hasan and Alam (2006) explored the potentials for agroforestry to minimize various types of land degradation in Bangladesh [14]. Sayeed (2014) investigated the causes and consequences of land degradation in the Keyain village of the central district of Munshigonj [15]. He found that due to land degradation, the agricultural land is decreasing annually due to several factors such as rapid population growth, improper use of land, lack of interest in agriculture, poverty, and conventional system of irrigation.

While the above-mentioned studies focused on land degradation in several regions of Bangladesh, a study examining the land degradation of the north-western region of the country is currently non-existent. This study aims to fulfill that gap by using GIS and remote sensing data to isolate and quantify areas that are vulnerable to environmental degradation in the Chapai Nawabganj and Naogaon districts in the north-western region of Bangladesh. Specifically, we first assessed five key indicators of environmental degradation parameters including 
soil, vegetation coverage, surface water coverage, temporal ground water pattern, and drainage networks within the study area. We chose the indicators based on the review of prior land degradation studies of Agyemang (2013) [16]. We then created a composite index of land degradation vulnerability by assigning and aggregating weights to each individual parameter. Finally, we suggested several recommendations for future planning and management to reduce land degradation in the vulnerable areas.

\section{Study Area}

The Nachole Upazila of the Chapai Nawabganj district and Niamatpur Upazila of the Naogaon district in the north-western region of Bangladesh were chosen as the main areas of study. With a total area of 732.28 square kilometer $\left(73,228\right.$ hectares) and an estimated population of 291,000 , the study area lies between $24^{\circ} 35^{\prime} \mathrm{N}$ to $24^{\circ} 55^{\prime} \mathrm{N}$ Latitude and $88^{\circ} 20^{\prime} \mathrm{E}$ to $88^{\circ} 40^{\prime} \mathrm{E}$ Longitude (Figure 1).

The study area falls within the Barind Tract, a part of the Bengal Basin. Although the Tract lies between the catchment of the Ganges River and its smaller tributaries including the Mahananda, Atrai, and Purnabhaba Rivers, a large section of it is suffering from extreme water scarcity. The annual temperature in the area varies between $8^{\circ} \mathrm{C}$ in the winter and $44^{\circ} \mathrm{C}$ in the summer months. The Monsoon season (June to October) covers $80 \%$ of total rainfall of the area with the other seasons covering the remaining $20 \%$ rainfall [17]. The imbalance of the seasonal rainfall affects the groundwater level and the local agricultural system. Average elevation from the mean sea level ranges between $22 \mathrm{~m}$ in western part to $40 \mathrm{~m}$ in the north-eastern part of the study area [17].

\section{Data Collection}

Due to the moderate to high spectral and spatial resolution, archival accessibility, and affordability, data from

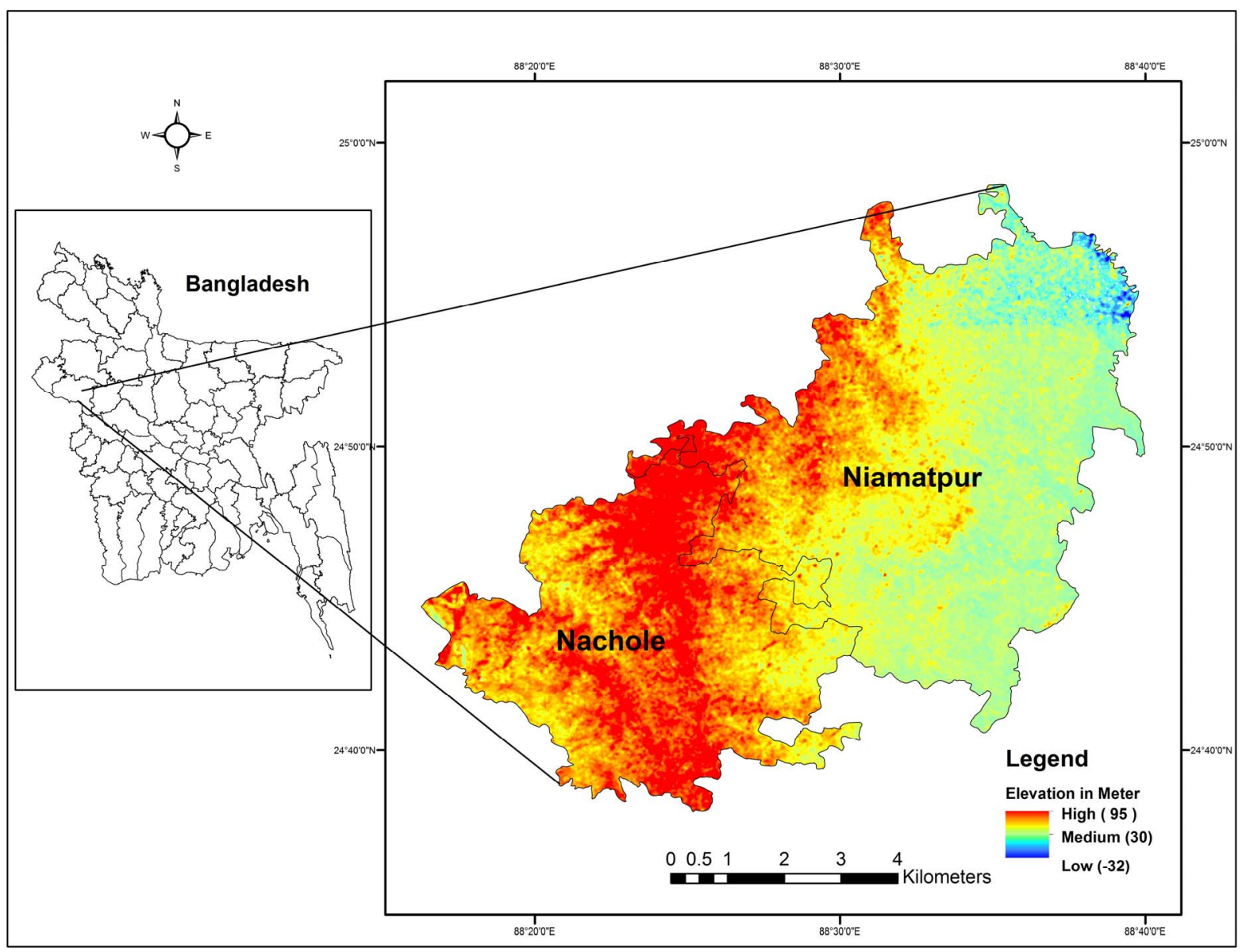

Figure 1. Location of map of the study area. 
the Landsat TM sensors were used to isolate areas of water, soil, and vegetation concentrations within the study area. A 30 m Digital Elevation Model (DEM) (collected through the ASTER sensor in 2002) was also used to derive the natural drainage networks and elevations. All Landsat imageries were freely obtained and downloaded from the University of Maryland's Global Land Cover Facility's Earth Science Data Interface (ESDI) website. The characteristics of the remote sensing data sets are given in Table 1.

In addition to the remote sensing data, ground water depth were also collected from 181 sample location points to investigate ground water deterioration. Groundwater is an important geographical factor, because it supports agriculture, safe drinking water, and overall biodiversity. Contamination of groundwater resources may cause severe environmental and health hazards [18]. To explore and identify the present declining rate of groundwater depth in the study areas, annual ground water depth database from 1986 and 2010 for the 181 points were collected from the Department of Public Health and Engineering (DPHE) of Bangladesh. The groundwater depth values were then interpolated as raster grid files and the differences between 1986 and 2010 were calculated.

\section{Methodology}

The aim of this study was to quantify the land degradation of the study area by assigning and aggregating weights to five individual indicators of land degradation. To fulfill that goal, some crucial steps for data processing and analysis were conducted. Figure 2 outlines the major steps that were undertaken:

Table 1. Characteristics of the remote sensing data used in the study.

\begin{tabular}{cccccc}
\hline \multirow{2}{*}{ Sensor } & \multicolumn{5}{c}{ Remote Sensing Data } \\
\cline { 2 - 5 } & Row/Path & Bands & Accusation Date & Projection & Resolution \\
\hline TM & $138 / 043$ & Blue, Green, Red, NIR, NDVI, TCT & $2013-011-2$ & UTM & 30.00 \\
TM & $138 / 043$ & Blue, Green, Red, NIR, NDVI, TCT & $1989-11-15$ & UTM & 30.00 \\
ASTER & -- & Topography, Drainage & 2002 & UTM & 30.00 \\
\hline
\end{tabular}

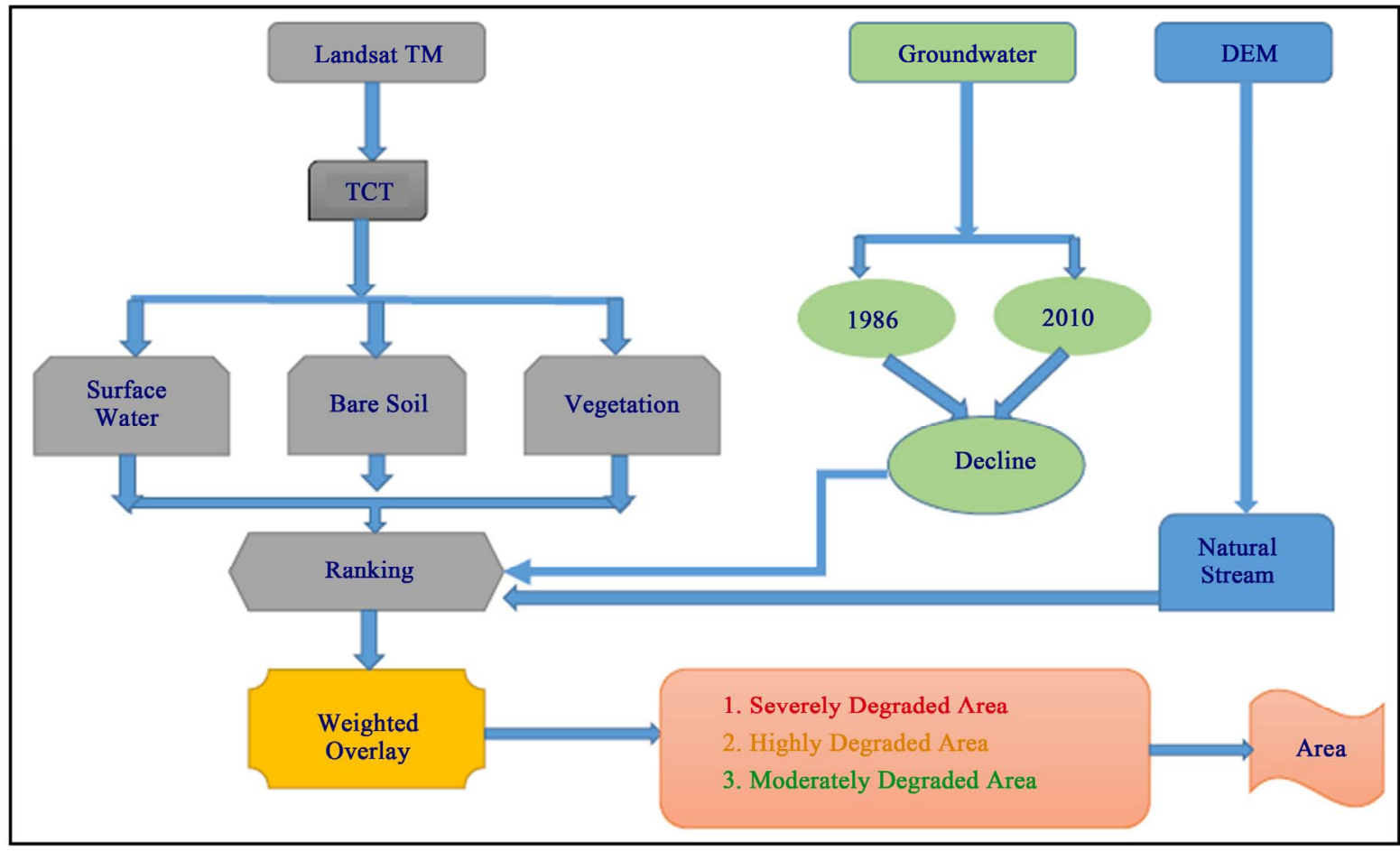

Figure 2. The overall methodological steps used in the study. 


\subsection{Processing of Remote Sensing Data}

We used the Landsat TM imagery of 2013 to extract areas of soil, vegetation and surface water bodies were within the study area. Tasseled Cap Transformation (TCT) was utilized in ENVI version 4.8 to extract these features.

The TCT is a linear transformation algorithm technique that reduces overlapping of multi-spectral datasets into fewer number of image sets based on particular scene characteristics [2]. After executing TCT on the Landsat data, three major components (I) soil brightness, (II) wetness and (III) greenness were derived and were used as the main sources for isolating areas of soil, vegetation, and surface water within the study area (Figures 3(a)-(c)). A threshold value with specific ranges based on field survey was developed to extract surface water, bare soil, and vegetation. Table 2 outlines the threshold ranges selected for the three parameters. The natural drainage networks density was derived from the DEM (Figure 3(d)).

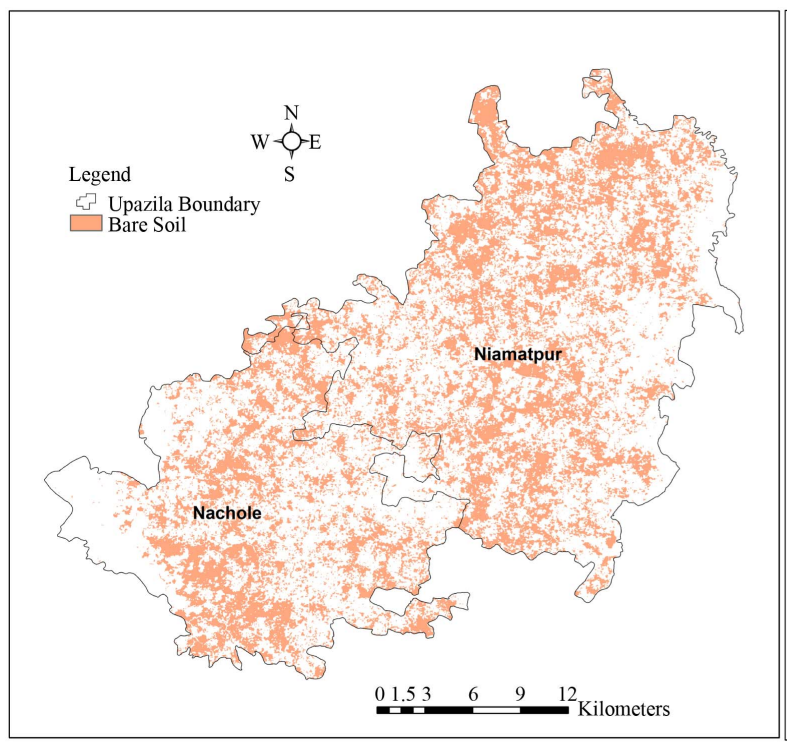

(a)

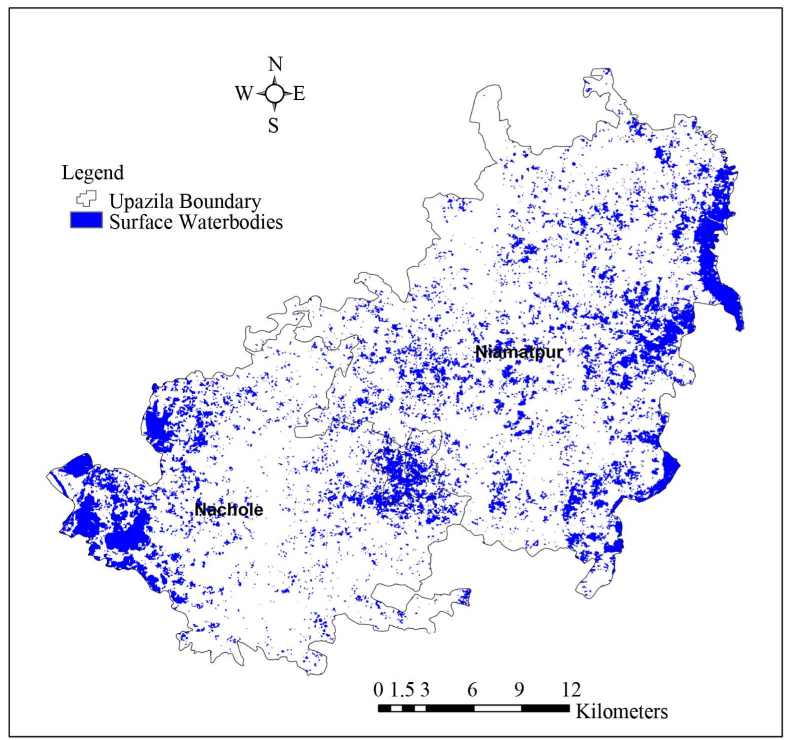

(c)

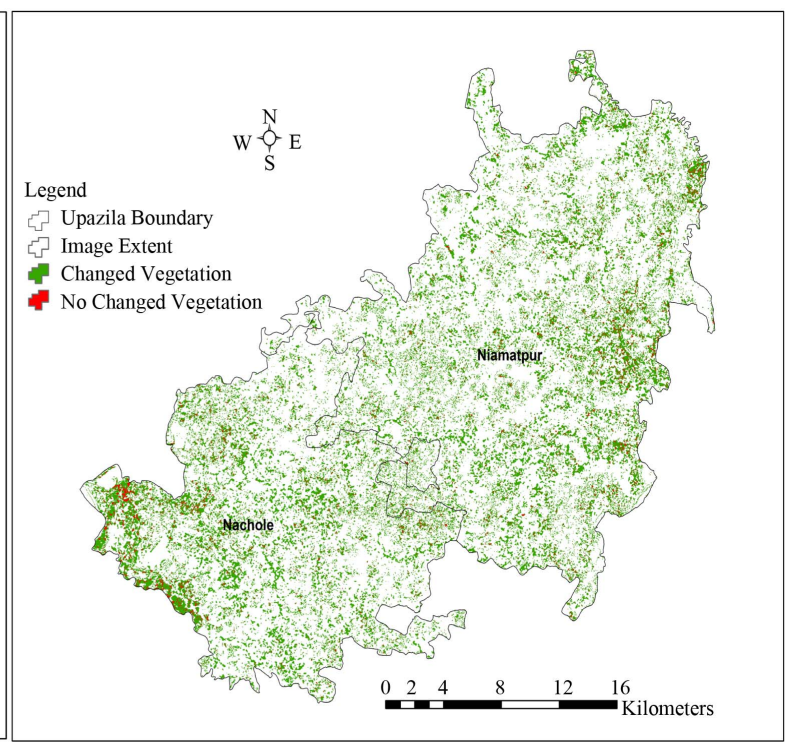

(b)

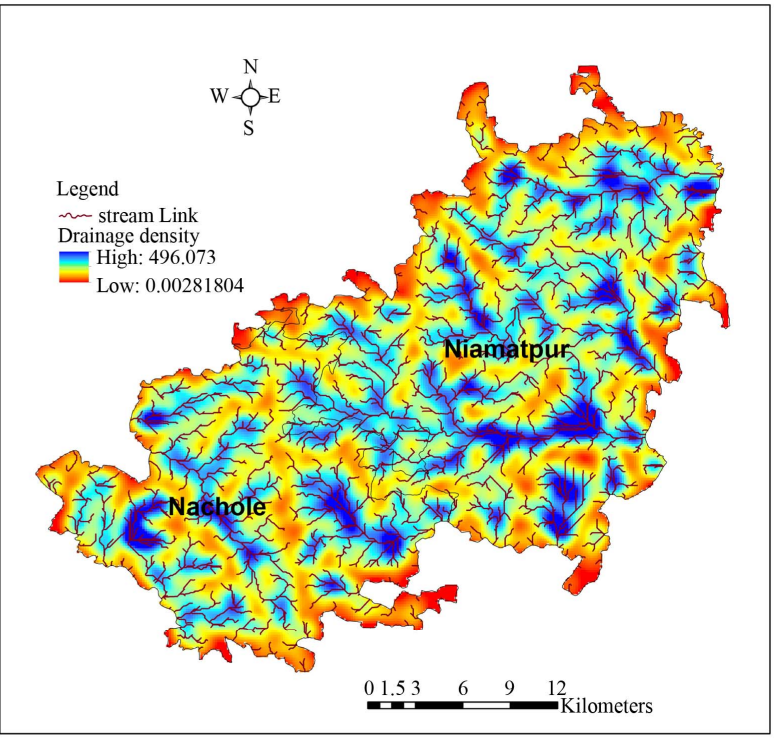

(d)

Figure 3. The major thematic maps of the study: (a) Soil coverage from the TCT; (b) Vegetation coverage from the TCT; (c) Surface water from the TCT; (d) Derived drainage network (in meters) from the DEM. 
In order to examine the accuracy of the land cover extraction and land degradation-modelled results, a random sample of 8000 reference pixels were selected within the study area. These pixels were compared with the extracted features. To present the accuracy assessment results, an error matrix was generated and the user's accuracy, producer's accuracy, overall accuracy, and the Kappa coefficient were calculated. A summary of the results are given in Table 3. For generating the whole accuracy assessment results e.g. error matrix, overall accuracy and kappa coefficient, the Equations (1)-(3) respectively used in this paper are in below

$$
\begin{gathered}
\text { Error matrix, } n=\sum_{i=1}^{K} \sum_{j=1}^{k} n_{i j} \\
\text { Overall Accuracy }=\frac{\sum_{i=1}^{k} n_{i i}}{n}
\end{gathered}
$$

where, $n_{i j}$ is diagonal elements in error matrix; $n$ is total number of samples in error matrix

$$
\text { Kappa coefficient, } K=\frac{n \sum_{i=1}^{k} n_{i i}-\sum_{i=1}^{k} n_{i+} n_{j}}{N_{2}-\sum_{i=1}^{k} n_{i+} n_{i}}
$$

where, $i$ is number of rows, columns in error matric; $N$ is total number of observations in error matrix; $n_{i j}$ is major diagonal element for class $i ; n_{i+}$ is total number of observations in row $i$ (right margin); $n_{+j}$ is total number of observations in column $i$ (bottom margin).

\subsection{Ranking}

To identify the areas that are vulnerable from degradation within the study area, all thematic maps were ranked into three categories. In this step, a Likert scale was used to rank the degraded areas from 1 to 3 , where 1 indicated moderately; 2 indicated highly; and 3 indicated severely degraded area. After ranking these, an Analytical Hierarchy Process (AHP) has been used to assign weights to the five thematic maps. The Analytic Hierarchy Process (AHP) is a theory of measurement through pairwise comparisons and relies on the judgments of experts to derive priority scales [19]. To get which thematic maps are most important and their relative weights in terms of vulnerability of land degradation, 0 - 9 pairwise scales was selected based on less to most importance levels until a strong consistency ratio using ArcGIS software. For example, relative importance between surface water and vegetation for land degradation is significant and its scale was high. Likewise all pairs were comprised based on expert knowledge and recommendations. Finally, all the rank scores for each indicator were entered into a weighted overlay model to produce a raster output map that would display the level of degradation for each pixel. Table 4 highlights the details of each parameter and their rank scores.

Table 2. Selected TCT range for the three major parameters.

\begin{tabular}{ccc}
\hline Sl & Feature & Threshold Range (DN Value) \\
\hline 1 & Surface Water & $100.00-185.00$ \\
2 & Bare Soil & $145.000-315.000$ \\
3 & Vegetation & $112.000-280.000$ \\
\hline
\end{tabular}

Table 3. Summary of accuracy assessment.

\begin{tabular}{ccccc}
\hline Feature & $\begin{array}{c}\text { Producer's } \\
\text { Accuracy (\%) }\end{array}$ & $\begin{array}{c}\text { User's } \\
\text { Accuracy (\%) }\end{array}$ & Overall Accuracy (\%) & Kappa Coefficient \\
\hline Surface Water & 95 & 97 & \\
Bare Soil & 89 & 92 & 95.40 \\
Vegetation & 87 & 91 & \\
Severely Degradation & 95 & 97 & \\
Highly Degradation & 97 & 96 & \\
Moderately Degradation & 96 & 98 & \\
\hline
\end{tabular}


Table 4. Five parameters and their ranks based on attribute.

\begin{tabular}{|c|c|c|c|c|c|}
\hline Sl & Parameters & Attributes & $\begin{array}{c}\text { Criteria } \\
\text { (DN/Raster Value) }\end{array}$ & Rank & Weight from AHP \\
\hline 1 & Surface Water & $\begin{array}{l}\text { Very High Concentration } \\
\text { High Concentration } \\
\text { Low Concentration }\end{array}$ & $\begin{array}{l}56 \text { to } 125 \\
20 \text { to } 56 \\
0 \text { to } 20\end{array}$ & $\begin{array}{l}1 \\
2 \\
3\end{array}$ & 18 \\
\hline 2 & Bare Soil & $\begin{array}{l}\text { Very High Coverage } \\
\text { High Coverage } \\
\text { Low Coverage }\end{array}$ & $\begin{array}{c}94 \text { to } 165 \\
36 \text { to } 94 \\
0 \text { to } 36\end{array}$ & $\begin{array}{l}1 \\
2 \\
3\end{array}$ & 22 \\
\hline 3 & Vegetation & $\begin{array}{l}\text { Very High Coverage } \\
\text { High Coverage } \\
\text { Low Coverage }\end{array}$ & $\begin{array}{c}187 \text { to } 401 \\
67 \text { to } 187 \\
0 \text { to } 67\end{array}$ & $\begin{array}{l}1 \\
2 \\
3\end{array}$ & 25 \\
\hline 4 & Groundwater & $\begin{array}{l}\text { Very High Depletion Rate } \\
\text { High Depletion Rate } \\
\text { Low Depletion Rate }\end{array}$ & $\begin{array}{l}-11.82 \text { to }-6.40 \\
-6.40 \text { to }-3.99 \\
-3.99 \text { to } 6.23\end{array}$ & $\begin{array}{l}3 \\
2 \\
1\end{array}$ & 20 \\
\hline 5 & Drainage Network & $\begin{array}{l}\text { Very High Density Network } \\
\text { High Density Network } \\
\text { Low Density Network }\end{array}$ & $\begin{array}{c}-217 \text { to } 496 \\
128 \text { to } 217 \\
0 \text { to } 128\end{array}$ & $\begin{array}{l}1 \\
2 \\
3\end{array}$ & 15 \\
\hline
\end{tabular}

\subsection{Weighted Overlay Modeling}

Weighted overlay technique is an important method for creating integrated outputs using multi-thematic databases. It applies a common measurement scale of values to diverse and dissimilar inputs to create an integrated analysis [20]. Based on the ranks, the five geo-parameters were entered in a weighted overlay model to identify and quantify environmental degradation using GIS. The following empirical weighted Equations (4) and (5) were used to execute the overlay model:

$$
\text { Land degradation }=\sum W * R \quad(W=\text { Weight of thematic map; } R=\text { Rank of each criteria })
$$

Explicitly:

$$
\begin{aligned}
\text { Land Degradation }= & \sum((\text { Surface water } W * \text { Surface water } R)+(\text { Bare soil } W * \text { Bare soil } R) \\
& +(\text { Vegetation } W * \text { Vegetation } R)+(\text { Groundwater } W * \text { Groundwater } R) \\
& +(\text { Drainage network } W * \text { Drainage network } R))
\end{aligned}
$$

\section{Results and Discussions}

Surface soil plays a vital role in growing plants and vegetation and reducing top soil erosions. However, low rainfall with lower water holding capacity of soil can lead to desertification and land degradation. From our analysis, it was found that the quantities of bare soil are high in the north-eastern, south-western and in the central parts of the study area (Figure 4(a)). The quantity of bare soil is lowest in the western parts.

Vegetation helps in stopping environmental degradation and loss of biodiversity. Based on the greenness analysis from the TCT outputs of 1989 and 2013, very low vegetation coverage were found in the north-eastern, south, and south-western parts of the study area. It is being increased an alarming situation for maintaining environment and ecological balance in the study area. Moreover from this change detection of vegetation mapping, it is revealed that about 14,470 hectares were changed (green color in Figure 4(b)) into bare soils whereas only 904 hectares stayed the same (red color in Figure 4(b)) in the study area. Most of the unchanged vegetation was found in areas with high concentrations of surface water due to high moisture and water availability.

Surface water is an important geo-factor for irrigation, aquaculture, and water related livelihoods. While surface water bodies can be found in few areas of the North-Eastern, South-Eastern, Western, and in some central parts of the study area, it is nearly absent throughout the two upazilas (Figure 4(c)). From the hydrological analysis, a high density of drainage networks was found in the Southern and lower Eastern parts of the study area (Figure 4(d)). Meanwhile, there is acute water stress in the high Barind tract regions, where surface water and groundwater have been depleting in an alarming rate due to sustained surface-groundwater pumping for irrigations and drinking by the residents [21]. As a result, land degradation is expected to arise in these areas as 


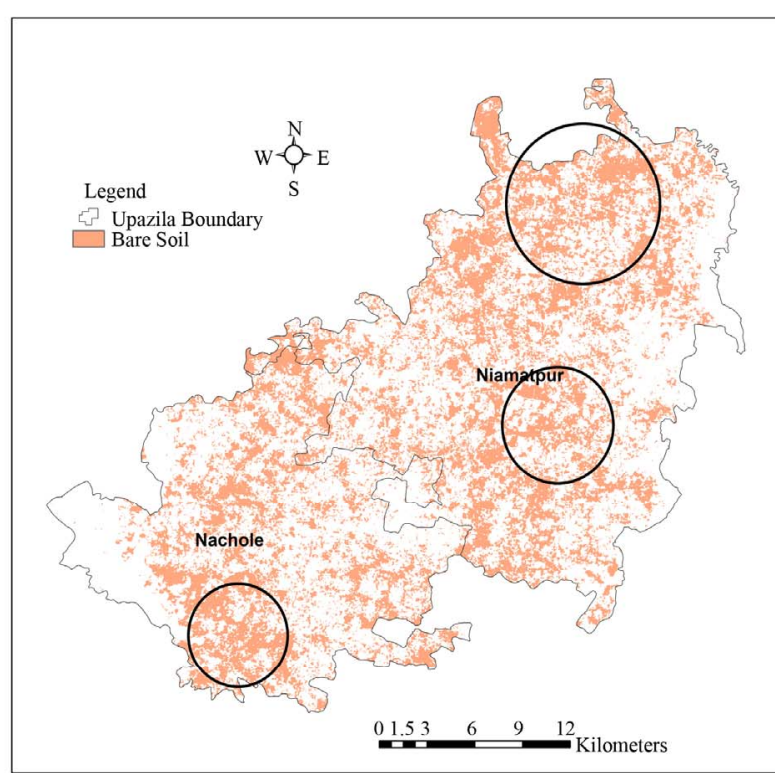

(a)

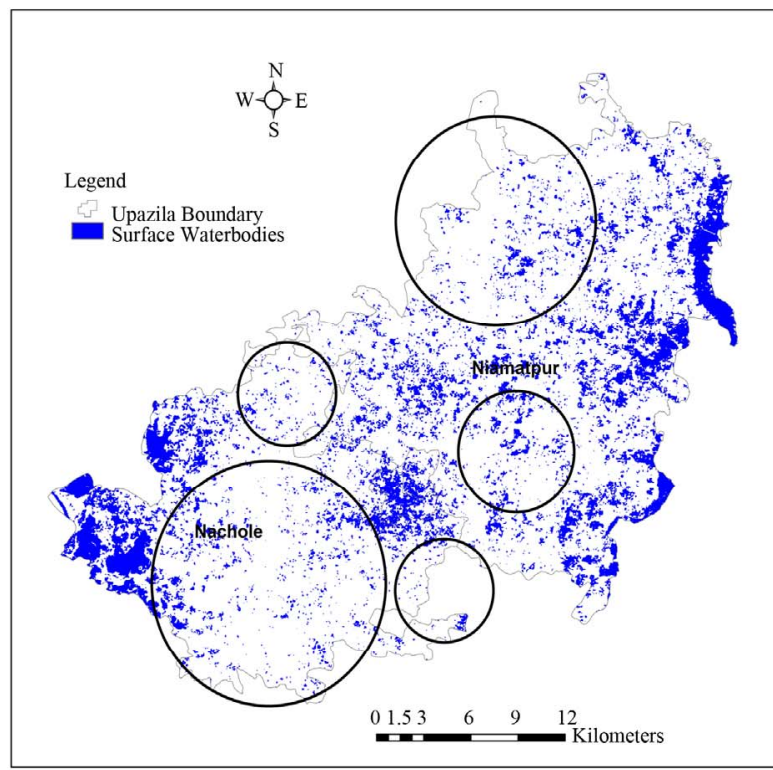

(c)

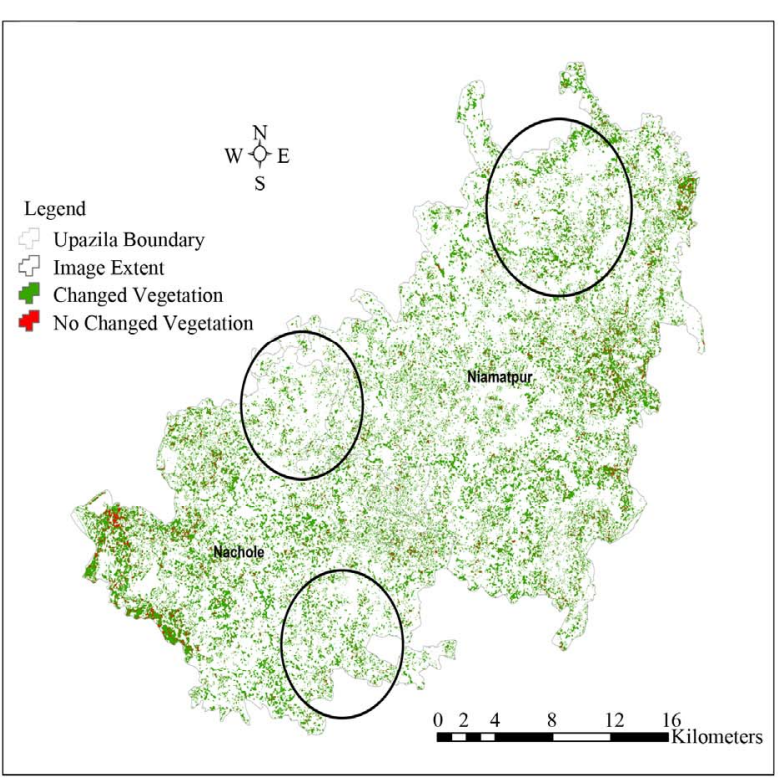

(b)

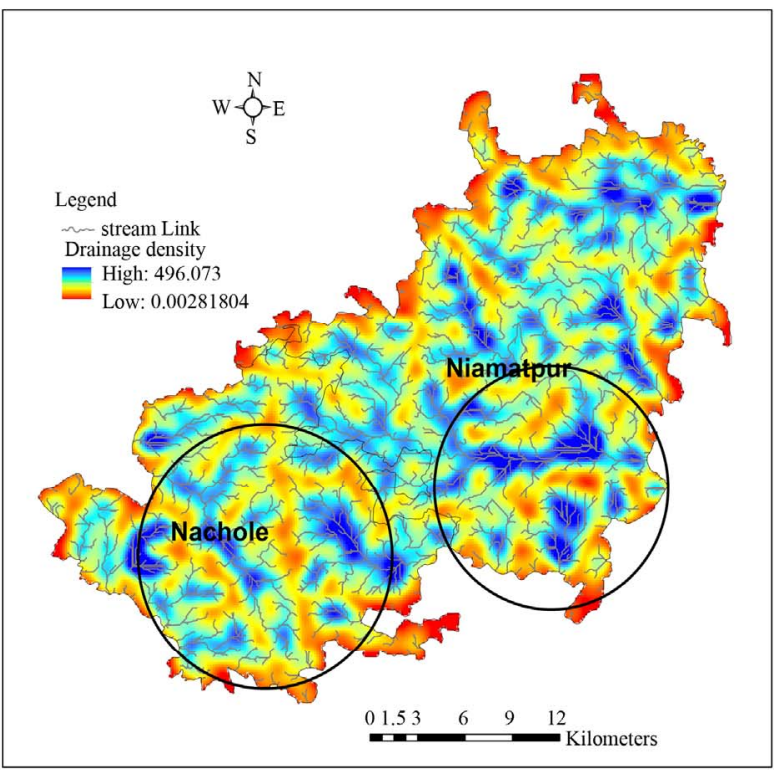

(d)

Figure 4. (a) Spatial distribution of base soil; (b) Spatial distribution of vegetation coverage; (c) Spatial distribution of surface water; (d) Spatial distribution of drainage network in the study area.

well.

Prolonged ground water depletion was found to be a common issue in the study area due to very low annual rainfall, dried up surface water bodies followed by lower recharge, excessive pumping of groundwater for irrigation and drinking purposes, hot climatic conditions, and soil properties. Moreover, people are extremely dependent on groundwater for irrigation and household purposes and it becomes the only source of water during dry periods in the region [22]. So, it has severe negative impacts on local biodiversity and ecology as well. In this study, ground water tables from 24 years have been analysed and the results reveals that high depletion rate of groundwater was found in the north eastern, South-Eastern, and in the central parts of the study area (Figure 5). Some groundwater recharging areas were also found in the western parts of the study area. Natural drainage system can hold water during dry season that could be used for irrigation and aquaculture. 


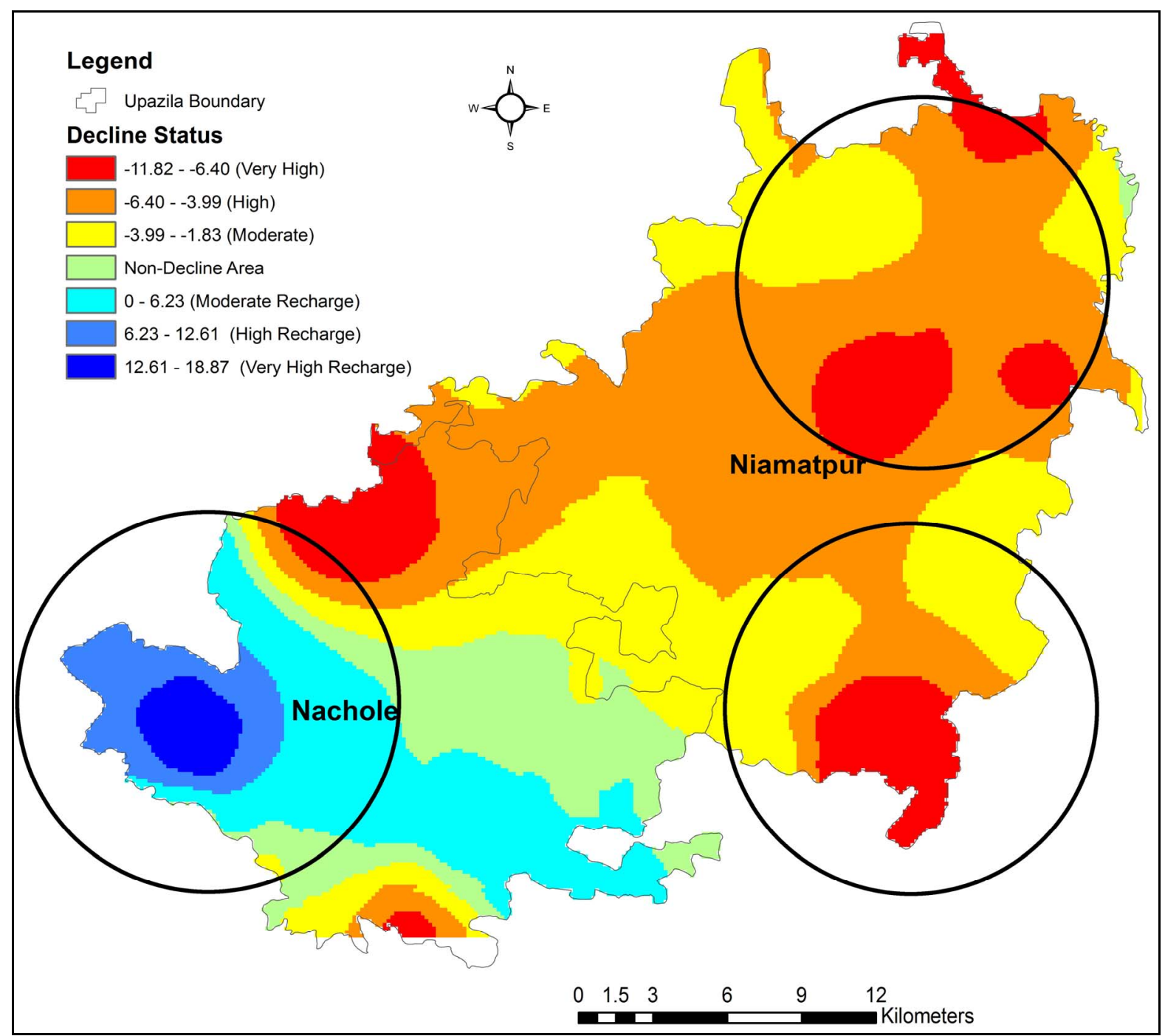

Figure 5. Spatial distribution of depletion of groundwater.

Results from the weighted overlay model suggest that a total about 66,301 hectares $(90 \%)$ of land are vulnerable to degradation (Figure 6 and Figure 7). Among them, 24,736 hectares (34\%) can be classified as severely vulnerable. These areas are found in the northern and North-Western parts. Approximately 40,309 hectares $(55 \%)$ can be classified as highly vulnerable and are distributed throughout the study area. Only 256 hectares of moderately vulnerable land were found in the western, eastern, and South-Western parts, through which there are plenty of surface water due to the existence of the Padma River.

Land degradation and desertification process in the Barind tract is progressing in an alarming level and requires urgent task to adopt suitable measures. Both natural and anthropogenic causes promote land degradation process. The recent inadequate rainfall and increasing temperature level over the region boosts the degradation phenomenon. Traditional crop (Aman, Irri, Boro paddy) cultivation also demands excessive water irrigation. Limited water bodies and wetlands of the area cannot fulfill the irrigation demand. The condition of the water bodies is also very poor due to less abundant rainfall. Therefore, power driven deep tube-wells are an alternate option to extract and use ground water for irrigation purpose. Excessive withdrawal of groundwater leads lowering the water table gradually and puts negative impacts on local vegetation. Huq et al. (2013) has described biomass overexploitation from the crop fields (used as fodder and firewood) to be another main reason for the land degradation in Barind tract [23]. Energy crisis leads overuse of biomass from harvested land and reduce vegetation cover. Consequently, topsoil cover becomes exposed. The process loses topsoil silty loam over clay 


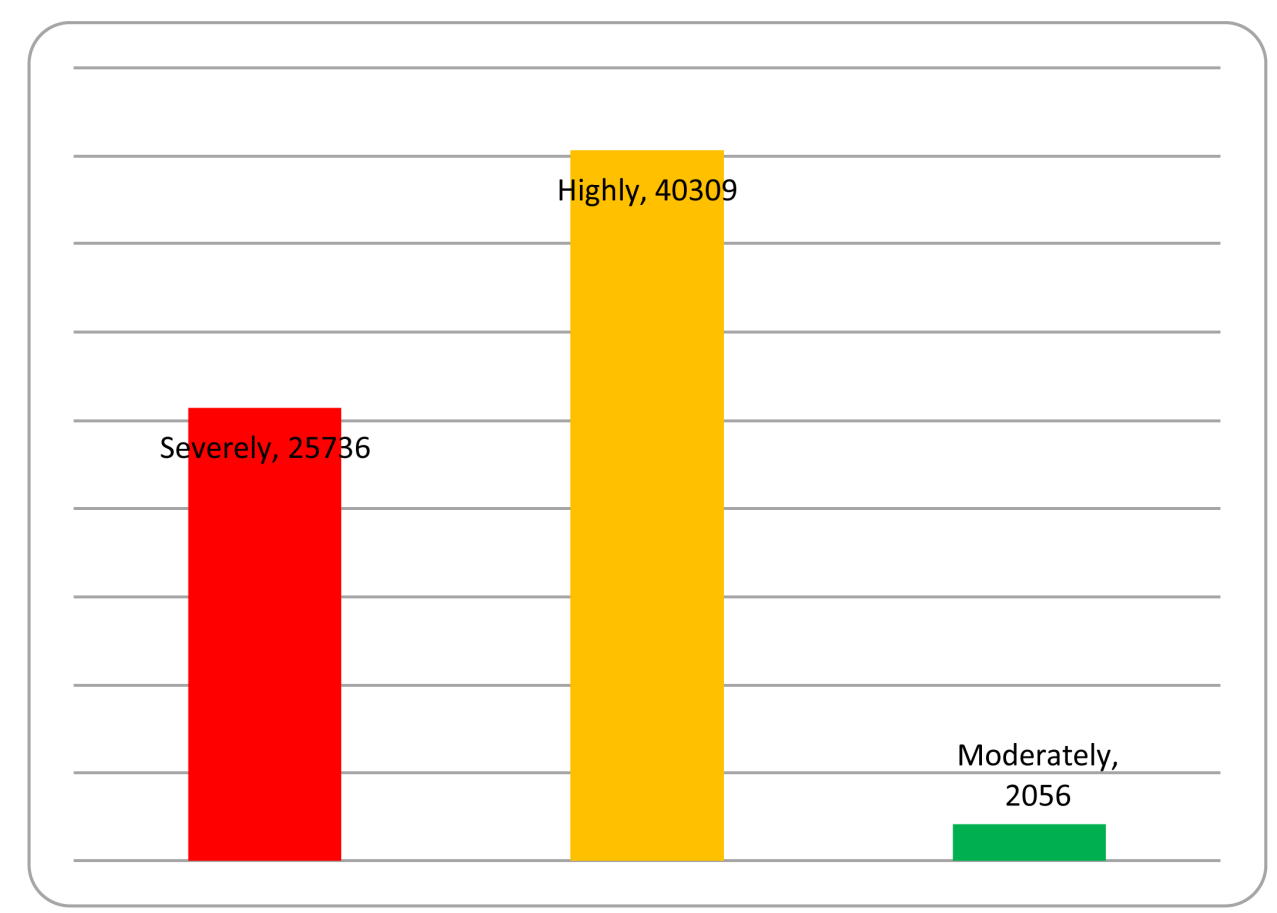

Figure 6. Level of vulnerability for land degradation within the study area.

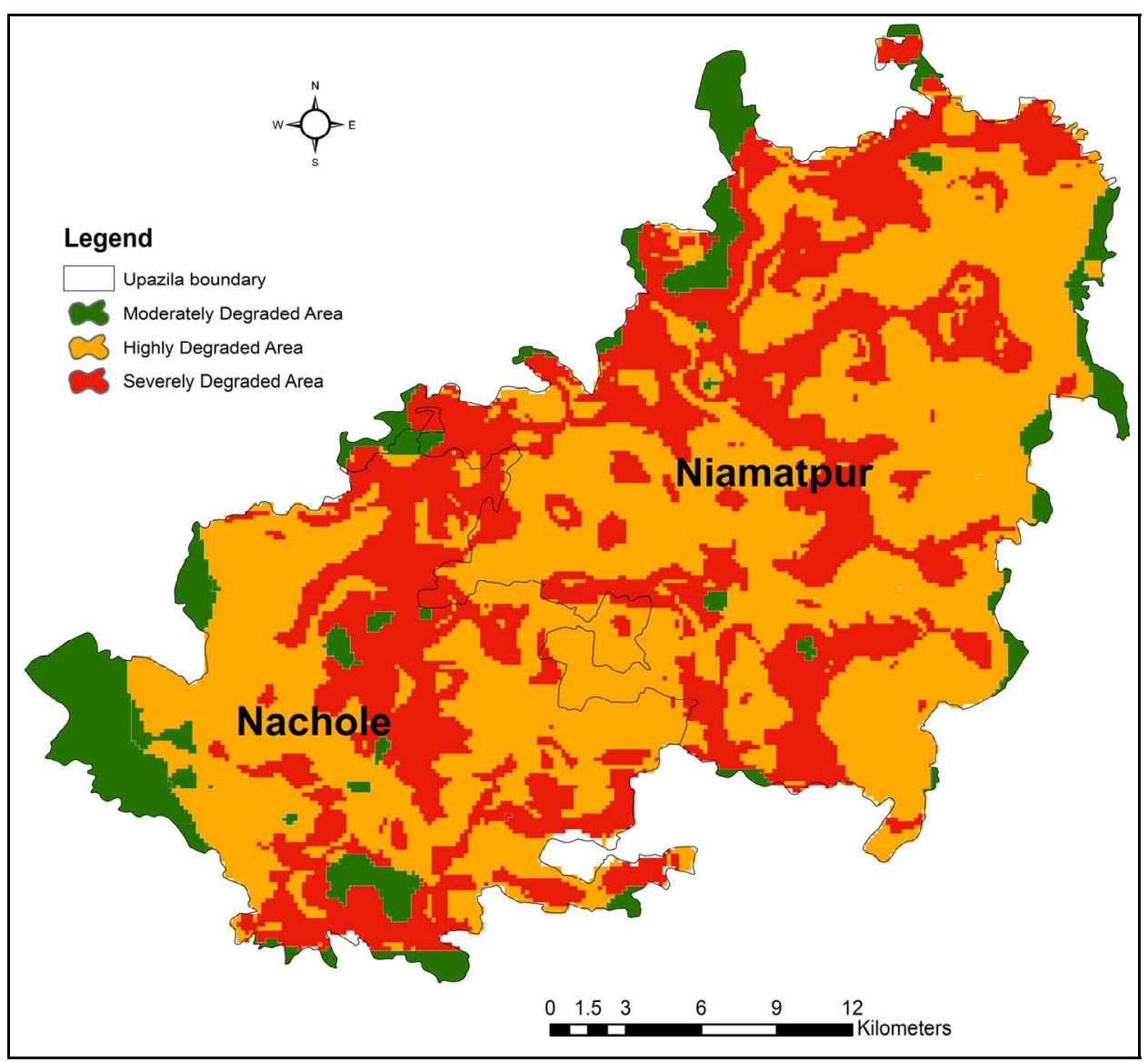

Figure 7. Spatial distribution of the land degradation vulnerability levels within the study area. 
layer. Clay has lower permeability and thereby, topsoil gets scarce water conservation competency. As a result, heavy rainfall during monsoon leads significant runoff and enhances land degradation process [23].

\section{Recommendations}

This study has identified areas that are vulnerable to land degradation in the north-western parts of Bangladesh. While the results suggest that majority of the study area are high to severely vulnerable, there are measures that can be taken to minimize the consequences of degradation. Some of these steps and measures are highlighted in the following sections.

Firstly, it is crucial that government policies, rules, and regulations regarding land degradation are carefully examined, revised, and enforced. One of the first government policies that should be revived are the policies on groundwater management. Even though existing policies are there, they need to be properly implemented. New rules and regulations must also be urgently passed that stops the illegal encroachment of existing drainage networks. The natural drainage networks that were grabbed illegally or filled up by sedimentation processes should be re-profiled, re-graded, and re-excavated to make sure water can pass freely. Integrated Water Resource Management (IWRM) policies should be introduced and enforced properly for all local and national drainage network systems. It is also necessary to have proper planning during any structural intervention in and within natural drainage networks that may cut-off water flow.

In agricultural lands, farmers should be encouraged to practice crop rotation processes that can prolong soil fertility and nutrients for future long-term cultivations. Instead of traditional crop cultivation, new crops should be considered which requires less irrigation. After harvesting period, farmers should keep crop residue and biomass on field to protect topsoil from being exposed and remain soil nutrients value. A long-term irrigation plan should be introduced in such a way that will decline ground water extraction without hampering the water level. It is also essential to limit the use of chemical fertilizers and encourage farmers to switch using organic fertilizers. Finally, local community leaders, civil society members, and other stakeholders can play a role in reducing the rate of land degradation by encouraging, motivating, and participating in social forestry programs.

\section{Conclusion}

Environmental degradation is a critical issue in Bangladesh, particularly in the north-western region of the country. It leads to geophysical and biological imbalance in the environment that contributes to lowering the national Gross Domestic Product (GDP) and affecting the socioeconomic conditions of the local villagers. From this study, it has been identified that the study area, a small portion of high Barind tract, is high to severely vulnerable degradation through many ways. Furthermore, GIS and remote sensing techniques have been found to be an essential and valuable tool to carry out the study objectives. Future studies should focus on using high resolution DEM and satellite data along with the biophysical characteristics to achieve more detailed assessments of the degradation conditions in the study area. Remedy to environmental degradation requires applicable government policies, and local initiatives from different stakeholders and community members.

\section{References}

[1] Lal, R. (1994) Soil Erosion Research Method. Soil and Water Conservation Society. St. Lucie Press, Delray Beach.

[2] Hassan, S. (2009) Assessment of Landuse and Land Degradation in the North-Western Part of Bangladesh Using Landsat Imagery. TRITA Master's Thesis, Division of Geoinformatics, Royal Institute of Technology (KTH), Stockholm, Sweden, 1-73.

[3] SLMP (2011) Sustainable Land Management Project. http://www.slmp.org.bd/

[4] Essa, S. (2004) GIS Modeling of Land Degradation in Northern-Jordan Using Landsat Imagery. Proceeding of the 20th ISPRS Congress, Istanbul, 12-23 July 2004, 505-510.

[5] Torrion, J.A. (2002) Land Degradation Detection, Mapping and Monitoring in the Lake Naivasha Basin, Kenya. ITC MSc Thesis, The Netherlands.

[6] Patanakanog, B., Sharestha, D.P., Saengthongpinit, C., Sapet, A. and Farshad, A. (2004) Land Use Change and Land Degradation: A Case Study in Nam Chun Sub Watershed in Thailand. Proceedings of the 25th ACRS, Chiang Mai, 22-26 November 2004, 1384-1389.

[7] Narangerel, D. (2001) Information System Design for Land Degradation Assessment, in Particular for Pasture Areas, 
Case Study of West Mongolia. ITC MSc Thesis, The Netherlands.

[8] Mohamed, E.S., Belal, A. and Saleh, A. (2013) Assessment of Land Degradation East of the Nile Delta, Egypt Using Remote Sensing and GIS Techniques. Arabian Journal of Geosciences, 6, 2843-2853. http://dx.doi.org/10.1007/s12517-012-0553-2

[9] Baroudy, A.A.E. and Moghanm, F.S. (2014) Combined Use of Remote Sensing and GIS for Degradation Risk Assessment in Some Soils of the Northern Nile Delta, Egypt. The Egyptian Journal of Remote Sensing and Space Sciences, 17, 77-85. http://dx.doi.org/10.1016/j.ejrs.2014.01.001

[10] El-Gammal, M.I., Ali, R.R. and Samra, R.M.A. (2015) GIS-Based Land Degradation Risk Assessment of Damietta Governorate, Egypt. Egyptian Journal of Basic and Applied Sciences, 2, 183-189. http://dx.doi.org/10.1016/j.ejbas.2015.01.001

[11] Rabia, A.H. (2012) GIS Spatial Modeling for Land Degradation Assessment in Tigray, Ethiopia. Proceedings of the 8th International Soil Science Congress on "Land Degradation and Challenges in Sustainable Soil Management", Vol. 3, Çeşme-Izmir, 15-17 May 2012, 161-167.

[12] Gafur, A., Jensen, J.R., Borggaard, O.K. and Petersen, L. (2003) Runoff and Losses of Soil and Nutrients from Small Watersheds under Shifting Cultivation (Jhum) in the Chittagong Hill Tracts of Bangladesh. Journal of Hydrology, 274, 30-46. http://dx.doi.org/10.1016/S0022-1694(02)00351-7

[13] Ali, A.M.S. (2006) Rice to Shrimp: Land Use/Land Cover Changes and Soil Degradation in Southwestern Bangladesh. Land Use Policy, 23, 421-435. http://dx.doi.org/10.1016/j.landusepol.2005.02.001

[14] Hasan, M.K. and Alam, A.K.M.A. (2006) Land Degradation Situation in Bangladesh and Role of Agroforestry. Journal of Agriculture and Rural Development, 4, 19-25.

[15] Sayeed, A. (2014) Causes and Consequences of Land Degradation. Master's Thesis, School of Life Science, Södertörn University, Södertörn.

[16] Agyemang, I. (2013) Environmental Degradation and Assessment: A Survey of the Literature. International Journal of Educational Research and Development, 2, 32-40.

[17] Reza, A.H.M.S. and Mazumder, Q.H. (2005) Evaluation of Hydrogeological Conditions of Sapahar and Porsha Upazillas, Barind Tract, Bangladesh. Journal of Life Earth Science, 1, 15-20.

[18] Rahman, M. and Shahid, S. (2004) Modelling Groundwater Flow for the Delineation of Wellhead Protection Area around a Water-Well at Nachole of Bangladesh. Journal of Spatial hydrology, 4, 13-22.

[19] Saaty, T.L. (2008) Decision Making with the Analytic Hierarchy Process. International Journal of Services Sciences, 1, 83-98. http://dx.doi.org/10.1504/IJSSCI.2008.017590

[20] ESRI (2010) How Weighted Overlay Works. http://webhelp.esri.com/arcgisdesktop/9.2/index.cfm?TopicName=How\%20Weighted $\% 20$ Overlay $\% 20$ works

[21] Hassan, S. and Moniruzzaman, M. (2010) Rule-Based Image Classification for Wetland Mapping of Godagari Thana of Rajshahi District, Bangladesh. The Journal of Geo-Environment, 9, 61-70.

[22] Shahid, S. and Hazarika, M.K. (2010) Groundwater Drought in the Northwestern Districts of Bangladesh. Water Resource Management, 24, 1989-2006. http://dx.doi.org/10.1007/s11269-009-9534-y

[23] Huq, S.M.I. and Shoaib, J.U.M. (2013) The Soils of Bangladesh. World Soils Book Series, Vol. 1, Springer Science \& Business Media, Dordrecht, 178. http://dx.doi.org/10.1007/978-94-007-1128-0 